\title{
Decentralized Marking of Tutor Marked Assignments in ODL: The Zimbabwe Open University Experience
}

\author{
Barnabas Muyengwa \\ Zimbabwe Open University, National Centre \\ Mount Pleasant, Harare \\ muyengwabb@gmail.com
}

\author{
Professor Richard Bukaliya \\ Zimbabwe Open University \\ Mashonaland East Region, Marondera \\ bukaliar@gmail.com
}

\begin{abstract}
This study aimed at establishing the tutors`and learners` perceptions of the centralised marking system versus the decentralised system, both of which had been tried at the Zimbabwe Open University. The study was qualitative case study in which a single case study design was adopted, the single case under investigation being ZOU Mashonaland East Region. Being a qualitative study, interviews were used to solicit data from the participants. The choice of case study and interviews was necessitated by the view that there was need for an in-depth understanding of the issue pertaining to tutor marked assignments. Out of the 15 tutor prospective participants, 5 were selected through convenience sampling. From the students participants, 12 were chosen through systematic sampling based on the lists provided at the Mashonaland East Registry office, for the July to December 2014 semester. The findings from the study show that the centralised marking that had been adopted by ZOU had a lot of drawbacks that affected both tutors and learners on one hand, and the administration on the other. The general view was that decentralized marking of assignments was more efficient in that students and tutors could easily follow up in the event of queries and clarifications. There was general consensus that an ODL institution like ZOU is decentralized and its activities like marking of assignments should be decentralized. In light of the findings it was recommends that decentralized marking of assignments processes in $O D L$ could be strengthened. Giving meaningful feedback to students could dictate the mode of marking assignments. It is also recommended that regional tutors should be directly involved in the assessment of their students.
\end{abstract}

Keywords: Decentralized marking, Tutor Marked Assignments, Open and Distance Learning, University experience.

\section{INTRODUCTION}

Open and Distance Learning (ODL) is a mode of delivery that entails that the learner and tutor are separated in terms of both space and time. It follows therefore, that most of the times they have to communicate in one way or the other through the most appropriate means of communication. Furthermore, since face to face contact is limited, there is need to make maximum use of all platforms that aid in the interaction process to facilitate effective learning. It is behind this background that the tutor has to make the most out of all the available platforms so that the learner benefits from the interaction. One of the important tasks of a tutor is the good practice of marking and commenting on assignments. It is through the comprehensive feedback by the tutors on the learners' assignments that learners are being "taught". Tutor Marked Assignments (TMA) play a crucial role in the assessment of students in ODL. The marking of coursework assignments is decentralized. The marking is done in the Regional Centres by the tutors who tutor the courses during the semester tutorials under the supervision of the Regional Programme Coordinator. That being the case though, during the July to December 2014 semester the Zimbabwe Open University (ZOU) attempted to centralize the marking of TMAs and this was received with mixed feelings amid fears that the programme had affected the quality of marking, on one hand, and that it was a step in the right direction for other. Full time faculty seem to be of the view that the marking of TMAs needs to be decentralized as this model has a number of educational sound merits than the centralized model. This study, therefore, was an attempt to establish the tutors' and learners` perceptions of the centralised marking system versus the decentralised system that had been practiced in ZOU hitherto.

\section{Statement of the Problem}

In ODL, the marking of assignments assumes a form of a delivery mode and as such plays a critical role in the teaching and learning process. Students and tutors have been engaged in a lively 
educational debate on the merits and demerits of the decentralized marking of coursework assignments in ODL. Attempts to centralize marking of assignments at ZOU met a number of challenges. This study seeks to find out students`and tutors' views on the centralized marking of coursework assignments.

\section{RESEARCH QUESTIONS}

The study aimed at addressing the following research questions which stood as sub problems:

1. What are the perceived merits of the decentralized marking of tutor marked assignments?

2. What are the perceived challenges of the centralized marking of tutor marked assignments in ODL?

3. Which is the preferred mode/option between centralized and decentralized marking as perceived by tutors and learners?

4. What are the suggested approaches for a hybrid strategy of marking of assignments?

\section{REVIEW OF RELATED LITERATURE}

\subsection{The Concept of Decentralisation as it Applies to TMAs}

This study adopts the view that a decentralised system in systems theory is a system in which lower level components operate on local information to accomplish global goals. The study also assumes that decentralization is the process of redistributing or dispersing functions, powers, people or things away from a central location or authority (Grindle, 2007). By this, we look at systems that are undertaken in an ODL organisation in light of the geographical dispersion of learners in an attempt to provide effective teaching and learning for the learner with all facilities and services being provided at the learner`s doorstep.

The study takes the stance that decentralisation is the way to go in all processes since the model describes the situation where the authority to make decisions is delegated to people at lower levels of the organisation where the real tasks of tutoring and learning are taking place (Bardhan, 2002; Allen, 2013). This often occurs where growth in size and increased complexity make the delegation of significant decision making authority necessary. According to Bardhan (2002), decentralisation is a matter of degree and is usually present to varying degrees in most organisations. This often occurs where growth in size and increased complexity make the delegation of significant decision making authority necessary. With the increased numbers of students in the various teacher development programmes at ZOU, surely decentralisation therefore, is key to success. It is fundamentally about making governance at the local level more responsive to the felt needs of the large majority of the population (Bardhan, 2002), and the case of ZOU, decentralisation becomes very responsive to the learners` needs.

\subsection{Perceived Merits of the Decentralized Marking of Tutor Marked Assignments}

\subsubsection{Promotion of Motivation}

Allen (2013) argues that decentralisation stimulates the formation of small cohesive groups. Since local managers are given a large degree of authority and local autonomy, they tend to weld their people into closely knit integrated groups. This improves the morale of employees as they get involved in decision-making process (Bardhan, 2002). Therefore, the more autonomy for Regional Programme Coordinators in the marking processes the better for them to boost their morale and effectiveness as they are involved in decisions of the small groups they lead at regional level (OseiKufuor and Bakare, 2013). It is, therefore, seen that decentralisation ensures better control and supervision as the subordinates at the lowest levels will have the authority to make independent decisions. As a result they have thorough knowledge of every assignment under their control and are in a position to make amendments and take corrective action (Saito, 2001).

\subsubsection{Quick Decision-Making}

Decentralisation brings decision making process closer to the scene of action (Allen, 2013). In the case of ZOU, the action is at most in the regional centres, hence those advocating for the decentralisation find support from Allen (2013). From a macro perspective, decentralisation brings public services closer to peoples, who have more opportunities to participate more actively in decision 
making process of local policies and activities than in centrally decided ones (Saito, 2001 OseiKufuor and Bakare; 2013). This leads to quicker decision-making of at the lower level since decisions do not have to be referred up through the hierarchy. The study also find meaning contributions from the writings by Coates et al. (1996). These enumerated the following advantages of decentralisation as follows:

- Specialisation. Managers can develop more detailed and specialised knowledge by concentrating on a limited aspect of the organisation's operations. This should result in better quality decisions.

- Timeliness. Quicker decisions are possible if it is not necessary to pass decisions up through the hierarchical chain of command. In addition, senior managers' time is then available for more important decisions affecting the future of the whole organisation.

- Motivation. Having authority to make decisions usually results in greater motivation and commitment and hence improved performance.

- Human resource development. Less experienced managers can 'learn their trade' without their mistakes jeopardising the entire organisation. The impact of mistakes/misjudgments is likely to be confined to a limited aspect of the organisation's operations.

- Organisational segment performance comparison. By dividing the organisation into separate segments, it is possible to evaluate which aspects of operations are performing well and which are not - something not usually possible when the inputs/outputs are at a more aggregate level.

\subsection{Perceived Challenges of the Decentralized Marking of Tutor Marked Assignments in ODL}

Decentralization of processes has also come with its own drawbacks. Under decentralisation, it is not possible to follow uniform policies and standardised procedures. Each manager will work and frame policies according to his talent (Saito, 2001; Grindle, 2007; Allen, 2013).

Some authorities have argued that decentralisation of authority creates problems of co-ordination as authority lies dispersed widely throughout the organisation (Allen, 2013). In support, Coates et al. (1996), state that decentralisation results in dysfunctional decision making. They argue that this occurs where managers take actions which improve the measured performance of their organisational segment, but damage the organisation as a whole. For example, a manager in one department may keep costs down in his/her own department in ways which have an impact on the quality of service provided to other departments.

There are possibilities and high prospects of a more financial burden if decentralisation is to be adopted (Allen, 2013; Grindle, 2007). Decentralisation requires the employment of trained personnel to accept authority, it involves more financial burden and a small enterprise cannot afford to appoint experts in various fields. Coates et al. (1996) argue that there is increased cost of control as costly management information systems may be necessary to monitor the performance of lower management levels to ensure that delegated decision making authority is being used in the best interests of the organisation.

Decentralisation puts more pressure on those leading the decentralised groups to realize results at any cost. Often in meeting their new targets, this could bring about conflicts among coordinators. Worse still, as argued by Coates et al. (1996), the issue of loss of control by senior managers results in further conflict. There is a danger that senior management may lose control of the organisation, as they become far removed from the detail of underlying operations and unaware of the decisions being made by lower level managers.

\subsection{The More Preferred Mode/Option between Centralized and Decentralized Marking as Perceived by Tutors and Learners}

From the above argument, one therefore, is left with opinion that where decentralisation is applauded by some, others have despised it. However, whereas in a decentralized approach services are delivered more speedily, that is not the case in a centralized administration. Furthermore, there is a belief that services become responsive to the different needs of different localities (Saito, 2001). This also results in more sustainable development outcomes because people can feel having more ownership of activities in which they are participating. The argument was therefore put to test in this present to ascertain the preferences of tutors and learners on the preferred approach to handling of TMAs. 


\section{Methodology}

The study was a case study based on qualitative research methodology. The researchers preferred the use of qualitative research methodology because of its ability to give the students and tutors' views on the centralized marking of coursework assignments. In this case study of ZOU Mashonaland East Region interviews were used to solicit data from the respondents. The choice of case study was necessitated by the view that there was need for an in-depth understanding of the issue pertaining to tutor marked assignments.

\section{Population and Sample}

The population for the study consisted of 58 prospective participants. Out of these were 15 tutors and 43 students. The tutors were drawn for the faculty list of those offering tutorials in the Teacher Development Programmes. Students were drawn from drawn from the PGDE, which had a total of 33 students and BECD programme which had a total of 10 students. Students in both programmes were returning students who had some experience with the manner in which TMA had been administered in the previous semesters. Out of the 15 tutor prospective participants, 5 were selected through convenience sampling. From the students` participants, 12 were chosen through systematic sampling based on the lists provided at the Mashonaland East Registry office, for the July to December 2014 semester. These participants responded to in-depth interviews.

\section{RESEARCH INSTRUMENTS}

In order to solicit data from the participants, open-ended interview questions were used. The questions were derived from the research questions and this permitted the researchers to go to town about given phenomena under study (Seale, 2006). The in-depth interviews enabled the soliciting of data to quite a great depth as the participants aired their views at length on the issue of decentralisation of TMAs.

\section{Presentation and Discussion of Research Findings}

From the findings, it can be noted that students and staff members made the following observations on the centralized marking of assignments:

\subsection{Perceived Merits of the Decentralized Marking of Tutor Marked Assignments}

Participants were asked to highlight the merits of decentralized marking of tutor marked assignments. The general view was that it was more efficient in that students and tutors could easily follow up in the event of queries and clarification in the assignments are marked at regional level as the markers are tutors of the programmes. Students and tutors will have interacted during tutorials and the expectations for each tutor marked assignment would have been explained. These findings agree with Osei-Kufuor and Bakare's (2013) observation that decentralization places emphasis on effectiveness and efficiency in decision making and implementation.

\subsection{Perceived Challenges of the Centralized Marking of Tutor Marked Assignments in ODL}

\subsubsection{Who should be marking the tutor marked assignments?}

The study's findings revealed that most of the participants were in agreement that the marking of assignments in ODL is much more than merely assessing a student's work. In view of this position, one participant reported that:

Marking of assignments especially in ODL, is part of the teaching methodology and as such the moment the tutor who interacts with the students in the teaching process is left out the methodology loses its effectiveness. The one who tutors should mark the assignments and give timely feedback to the student. In the last semester student were deprived of this important feedback.

In view of this, it is important that students receive timely feedback as observed by Saito (2001) who indicated that in the decentralized discourse services are delivered more speedily than in the case of a centralized administration. This should therefore be the case with ZOU which has eleven decentralised regions to offer services to the students nearer their homes. 
8.2.2. What is the Connection between Tutorials and Assignment Marking?

One of the exciting findings from the study was that assignment marking was considered as part of tutorials. This position was echoed by one tutor who pointed out:

At tutorial sessions we impact skills on avoiding plagiarism through appropriate referencing. We also impart skills on sustaining an argument. These are crucial skills that cannot be included in a marking guide. So by marking assignments centrally, tutorials are being conducted without this crucial teaching exercise. Therefore, while from a psychometric and pedagogical perspectives it is possible to centralize examinations but it is not possible to centralize marking of assignments.

\subsubsection{What Challenges are Created when the Tutor is not Involved in the Marking of TMA?}

Common among the responses from the participants was the view that centralized marking of assignments had a negative impact on feedback as it deprived tutors of giving meaning feedback to their students. The majority $(80 \%)$ of the tutors in the regions who interacted with the students on a face to face basis did not receive feedback on their students performance in order to allow them to give meaningful feedback for the next assignment and examinations.

One of the challenges that emerged from the study, according to all the five tutors, was that in the case of centralized marking there was no ownership of the student assessment as the regional tutors were not directly involved in the marking of the assignments. One of the 12 students participant said she got no help when she approached her regional tutor querying a low grade on a tutor marked assignment. She said the regional tutor put it this way:

It is difficult to assist you as I am not the one who wrote these comments. Commenting on the marker's views would be unfair as we seem to have different views on the issues you highlighted in your presentation.

8.2.4. How has the Centralised System Impacted on the Work of the Few Individuals Assigned to Mark Distribute, Coordinate and Supervise the Marking of TMA?

The study found out that centralized marking of assignments resulted in the over whelming overload of staff at the National Centre as they had other duties of preparation of marking guide, registration packages, examination items, module writing, development of programme regulations etc. In addition to these duties lecturers at the National Centre have additional tasks in the form of marking assignments, coordinating the marking process and capturing of marks. While this over whelmed National Centre staff, data capturing clerks in the Regions were left with nothing to do. Additionally, according to 4 tutor participants, academic staff members in the regions far away from the National Centre were excluded from this important exercise. Generally, this exercise resulted in great stress on National Centre staff and also compromised the quality of work.

\subsection{What Other Challenges have been faced in the Process of TMA Decentralization?}

\subsubsection{Perennial Submission of Assignment}

A big challenge was on the never ending submission of assignments to National Centre for marking. The perennial submission of assignments resulted in the perennial marking of assignments which coincided with the marking of examination. Moreover, the marking period was too short for such an important exercise as some time was also lost as assignments were transported to and fro between regional centres and the National Centre.

\subsubsection{Queries on TMA}

As highlighted above, regional staff could not assist students who raise queries on poorly marked assignments as they could not identify the markers. This greatly compromised the efficiency and effectiveness expected in a decentralized set up (Osei-Kufuor and Bakare, 2013)

\subsubsection{Lack of Transport Arrangements to Ferry TMA}

It also emerged from all the 5 tutors who took part in the study that the security of assignments was a challenge. Responses showed that student's assignments were security items and lecturers could not be seen carrying the assignments using public transport. This was confirmed by one participant who said: 
In the last semester lecturers were asked to carry assignments to Regions using public transport.

It can be deduced that decentralized marking could have minimised the security risks which were encountered thus vindicating the group advocating for decentralised marking.

\subsubsection{Non-Receipt of TMA by Some Students}

Another challenge from the study was the non-receipt of tutor marked assignments by some students. Among some of the queries raised in the Regions was the case of students who did not receive their marked assignments.

\subsection{The More Preferred Mode/Option between Centralized and Decentralized Marking as Perceived by Tutors and Learners}

The Faculty of Arts and Education students and tutors strongly feel that the faculty reverts back to the old model of marking assignments in line with the decentralized nature of the University. There was resentment from three of the tutors who remarked that they had lost out on remuneration for the TMA. Since they received no allocation, they were not entitled to anything except for the payment for tutorial attendance. One remarked that it was not the issue of remuneration but rather wanting to provide feedback to learners on their performance which they were not able to do because they were not part of the marking team. Learners too were not satisfied by the quality of marking and the expectation of those that marked. One indicated that she had followed the advice of the tutor at the tutorials only to have all the ideas shot down by the marker. With these views in mind, the general feeling was that there was need for decentralised marking.

\subsection{Suggested Approaches for a Hybrid Strategy of Marking of Assignments}

On what other approaches could be adopted by ZOU all the 5 tutors and nine students indicated that ZOU as an ODL institution was decentralized and thrived on that concept of decentralization. Whenever possible the activities of the University should remain decentralized. With the anticipated increased enrolment centralized marking of assignments was no longer feasible. However, some were of the opinion that centralised marking was workable where all tutors for all the regions were involved. One participant indicated that centralised marking could take place at a venue where all tutors were to be involved so as to facilitate giving feedback to the learners they taught. However, this could mean a lot of financial injections for venue hire as well as for the upkeep of the staff thereby making it more expensive that the decentralisation and besides it defeats the belief that services become responsive to the different needs of different localities (Saito, 2001) where there is decentralization.

\section{Conclusions}

Based on the foregoing findings, the study concludes that:

- The centralised marking that had been adopted by ZOU had a lot of drawbacks that affected both tutors and learners on one hand, and the administration on the other.

- The general view was that decentralized marking of assignments was more efficient in that students and tutors could easily follow up in the event of queries and clarifications.

- In centralized marking there was no ownership of the student assessment as the regional tutors were not directly involved in the marking of the assignments.

- Assignment marking was considered as part of tutorials in ODL.

- An ODL institution like ZOU is decentralized and its activities like marking of assignments should be decentralized.

\section{RECOMMENDATIONS}

In light of the above conclusions, this study recommends that:

- Decentralized marking of assignments processes in ODL could be strengthened through teams that tutor similar courses and present immediate feedback to learners.

- Assignment marking could be considered as part of tutorials to enhance the learning process, hence centralizing the process could defeat the whole process of ODL that entails bringing ODL to the learners` doorsteps. 
- Giving meaningful feedback to students could dictate the mode of marking assignments.

- All regional tutors in ZOU should be directly involved in the assessment of their students and as such no one should be left out of marking process.

- Where funds do not permit for a purely decentralised marking session, a hybrid model could be adopted where regions in the vicinity of each other could be bunched but at the same time making use of all human resources in the bunched regions.

\section{REFERENCES}

Allen, L.A. (2013). Management and Organization: McGraw-Hill Series in Management Paperback. New York: McGraw Hill Series.

Bardham, P. (2002). Decentralization of Governance and Development. Journal of Economic Perspectives. Volume 16, Number4:185-205.

Coates, J.B., Rickwood, C. and Stacey, R.J. (1996). Management Accounting for Strategic and Operational Control, Oxford, Butterworth-Heinemann.

Faguet, Jean-Paul (Ed.). (2014). "Decentralization and Governance." Special Issue of World Development. 53: 1-112.

Grindle, M.S. (2007). Going Local: Decentralization, Democratization, And The Promise of Good Governance, Princeton University Press.

Osei-Kufuor, P. and Bakare, I. (2013). Conceptualizing Institutionalised Decentralisation: Implications for Competing Theories in Development. International Journal of Humanities and Social Science Invention. Volume 2, Issue 9. September 2013:32-45.

Saito, F. (2001). Decentralisation Theories Revisited: Lesson from Uganda. Rvakoku RISS Bulletin Number 3 March 2001.

\section{AuthORS' BIOGRAPHY}

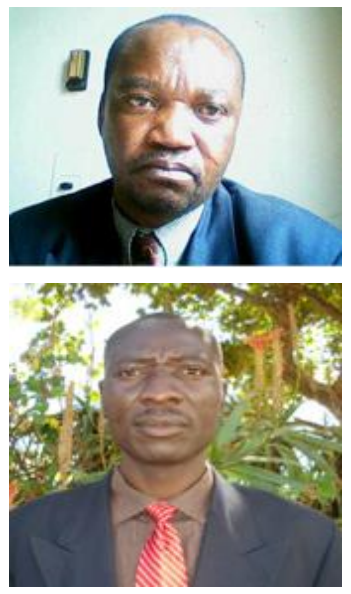

Mr. Barnabas Muyengwa is a Senior lecturer and National Programme Leader for the Bachelor of Education in Curriculum Studies and Post Graduate Diploma in Education (PGDE) in the Faculty of Arts and Education at the Zimbabwe Open University. He has published and reviewed articles in international peer reviewed journals. He has presented research papers at international and local conferences.

Richard BUKALIYA, is a Professor teaching at the Zimbabwe Open University in the Faculty of Arts and Education. He is the Regional Programme Coordinator in the Department of Teacher Development. His research interests include issues in Distance Education and Primary and Secondary education. The researcher has, to date, published several research articles in several international journals. He has presented papers at conferences locally and internationally. He is on the review boards of several international research journals which include the International Journal of Social Sciences and Education (IJSSE), The International Journal of Educational Research (JER), Greener Journals and the Global Research Journal of Education. 